\title{
Por uma sociologia reflexiva do esporte: considerações teórico-metodológicas a partir da obra de Pierre Bourdieu
}

\author{
Juliano de Souza* \\ Wanderley Marchi Júnior**
}

\begin{abstract}
Resumo: No presente artigo, procura-se apresentar e discorrer sobre alguns aspectos de reflexividade pertinentes à teoria do campo esportivo de Pierre Bourdieu. Para essa investida, sentiu-se a necessidade de se concentrar em três pontos de sustentação teórico-metodológicos trabalhados rigorosamente pelo autor, quais sejam: (1) a reflexividade epistemológica; (2) o papel do conhecimento histórico nas análises sociológicas do esporte; (3) a orientação do consumo esportivo no sentido de consolidação de um espaço social associado à lógica da distinção.

Palavras-chave: Sociologia. Esportes. Pierre Bourdieu.
\end{abstract}

\section{INTRODUÇÃo}

Em inúmeras oportunidades de sua obra, o sociólogo francês Pierre Bourdieu se refere ao fato de utilizar a sociologia contra suas próprias determinações, argumentos e limites sociais, tentando assim fornecer e sistematizar elementos para uma análise sociológica do desenvolvimento do seu trabalho. (BOURDIEU, 1990a; BOURDIEU, 2005).

O que o autor, de antemão, está sugerindo, obviamente, não se restringe apenas ao questionamento de seu papel enquanto cientista social, ou então enquanto um pesquisador que, ao longo de sua trajetória acadêmica, formulou e sistematizou uma sofisticada teoria sociológica - uma abordagem que, se não é possível chamar de acabada, ao menos pode-se conferir um status muito próximo de tal intento.

\footnotetext{
* Mestrando em Educação Física. Centro de Pesquisas em Esporte, Lazer e Sociedade (CEPELS). Departamento de Educação Física da Universidade Federal do Paraná. Curitiba, PR, Brasil. Asociación Latinoamericana de Estudios Socioculturales del Deporte (ALESDE). E-mail: julianoedf@yahoo.com.br

** Doutor em Educação Física. Centro de Pesquisas em Esporte, Lazer e Sociedade (CEPELS). Departamento de Educação Física da Universidade Federal do Paraná. Curitiba, PR, Brasil. Asociación Latinoamericana de Estudios Socioculturales del Deporte (ALESDE). E-mail: marchijr@ufpr.br
} 
De forma mais precisa, ao se colocar e colocar suas formulações em xeque num exercício de autossocioanálise, Bourdieu procura frisar a importância de se avançar rumo a uma sociologia da sociologia, quer dizer, a uma sociologia do fazer sociológico. Esse empreendimento Bourdieu denominou de sociologia reflexiva, ${ }^{1}$ a qual, de modo mais específico, consiste num exercício de conversão pessoal (meio de corpo e alma) ao ofício sociológico.

Conforme Bourdieu, a profissão de sociólogo requer a incorporação de um novo habitus intelectual, cuja particularidade reside na interiorização dos princípios constituintes e norteadores de sua teoria do conhecimento sociológico. Nesse sentido, um novo habitus sociológico, tal como Bourdieu concebe, é o que permitiria ao pesquisador construir um objeto de pesquisa segundo os princípios de construção do próprio objeto.

Exatamente por isso é que Bourdieu (1983a) não entende a sociologia do conhecimento como uma especialidade dentre outras, mas como um dos requisitos primeiros para a constituição de uma sociologia propriamente científica. Dessa forma, a sociologia do conhecimento de Bourdieu, ao mesmo tempo, remonta e transcende a tradição sociológica durkheimiana, tendo por objetivo romper com toda espécie de espontaneísmo e ideologia. De outro modo, Bourdieu procura instaurar uma perspectiva de apreensão do mundo social onde o sociólogo não renuncia ao seu privilégio epistemológico de explicação dos fatos sociais, mas também não desconsidera o valor das experiências dos agentes num universo empiricamente delimitado. (BOURDIEU; CHAMBOREDON; PASSERON, 1999). ${ }^{2}$

Nas linhas que seguem, pretende-se discorrer sobre alguns aspectos de reflexividade investidos na elaboração do modelo de análise

\footnotetext{
${ }^{1}$ Além de orientar a construção do pensamento e teoria sociológica de Pierre Bourdieu, a sociologia reflexiva também foi escopo de análise, em especial, nas seguintes obras: BOURDIEU, $\mathrm{P}$. Introdução à sociologia reflexiva. In: O poder simbólico. Lisboa: Difel, 1989, p. 18-56; BOURDIEU P.; WACQUANT, L. Una invitación a la sociología reflexiva. 2 ed. Buenos Aires: Siglo XXI Editores Argentina, 2008. (Publicado pela primeira vez e originalmente com o título: BOURDIEU, P.; WACQÜANT, L. An invitation to reflexive sociology. Chicago: The University of Chicago Press, 1992).

2 Uma análise mais acurada da herança durkheimiana na construção da sociologia de Pierre Bourdieu foi desenvolvida por: WACQÜANT, L. Durkheim e Bourdieu: a base comum e suas fissuras, Novos Estudos, CEBRAP, n. 48, p. 29-38, jul. 1997.
}

Movimento, Porto Alegre, v. 16, n. 01, p. 293-315, janeiro/março de 2010. 
sociológica dos campos de Pierre Bourdieu, mais especificamente em sua forma adquirida e explicitada na construção da teoria do campo esportivo. Para essa investida, sentiu-se a necessidade de se concentrar em três pontos de sustentação teórico-metodológicos trabalhados rigorosamente por Bourdieu ao longo dos textos no qual o autor se dedicou à análise do fenômeno esportivo, quais sejam: (1) a reflexividade epistemológica; (2) o papel do conhecimento histórico nas análises sociológicas do esporte; e (3) a orientação do consumo esportivo no sentido de consolidação de um espaço social associado à lógica da distinção.

\section{A sociologia do campo esportivo de Pierre Bourdieu}

As contribuições de Pierre Bourdieu para o desenvolvimento de um campo científico de pesquisas e estudos voltados para sociologia do esporte são notórias, fundamentais e vão muito além do que ter escrito dois ou três textos tratando especificamente do assunto ou então ter dedicado alguns números de sua revista Actes de La Recherche en Sciences Sociales à discussão das práticas e consumos esportivos. Pelo contrário, a força de sua abordagem não se singulariza apenas nesse itinerário, mas na originalidade do método que o autor fornece para trabalhar o esporte na esteira da reflexividade. ${ }^{3}$

Diante dessa conjuntura inferida e em conformidade com os pressupostos sustentados pelo sociólogo francês Loïc Wacquant (2008), foi possível identificar no mínimo duas perspectivas de apropriação da teoria sociológica de Pierre Bourdieu para estudar o esporte. Uma primeira maneira mais pontual e que consiste em utilizar e estender seus conceitos como ferramentas de leitura e análise de determinada realidade empírica. Outra forma mais abrangente e que preza pela lealdade acadêmica preservada ao método sociológico por ele desenvolvido. ${ }^{3}$ Outros estudos também têm se preocupado em recuperar as contribuições teórico-metodológicas
de Bourdieu para potencializar a análise dos mais distintos objetos e campos sociais. Na socio-
logia da saúde, por exemplo, têm-se as inserções do pesquisador Miguel Ângelo Montagner (2006;
$2008)$, que procura recuperar a teoria sociológica bourdieusiana para pensar alguns aspectos
relativos à temática da saúde e que, inclusive, fornecem alguns apontamentos e diretrizes para
pensar a distinção social, os estilos de vida e as próprias construções sociais do corpo. Já na
sociologia da educação, é importante destacar o trabalho de Afrânio Mendes Catani (2002), o
trabalho de Cláudio Marques Martins Nogueira e Maria Alice Nogueira (2002), a tese de doutorado
de Cristina Carta Cardoso de Medeiros (2007) e, mais recentemente, seu texto publicado em
parceria com Wanderley Marchi Júnior (2009).

Movimento, Porto Alegre, v. 16, n. 01, p. 293-315, janeiro/março de 2010. 
Essa segunda via de assimilação é, segundo Wacquant (2008), aquela que potencialmente permite aos cientistas sociais (dentre esses, aqueles que se dedicam à análise do fenômeno esportivo) trilhar um caminho de reflexividade tal como Bourdieu preconizava. Isso porque utilizar o método de investigação aprimorado por ele pressupõe que o pesquisador já detém certo domínio sobre as ferramentas básicas de apreensão do mundo social (habitus, campo, capital), ao mesmo tempo em que já tem incorporado as referências de que para compreender a fundo determinado espaço é também necessário problematizar a gênese do conhecimento anteriormente produzido sobre este mesmo espaço. (BOURDIEU; CHAMBOREDON; PASSERON, 1999).

Por conseguinte, tal resgate histórico da produção de conhecimento sociológico vinculado ao universo dos esportes conserva suas próprias especificidades, não devendo, por isso, ser confundido com aquela etapa integrante de todo trabalho acadêmico e que consiste em apresentar uma revisão de literatura, um levantamento bibliográfico, ou então, de maneira mais exaustiva, um mapeamento sobre o estado da arte do tema a ser pesquisado.

Enfim, esse inventário da produção do conhecimento atrelado a determinado campo científico é introduzido na sociologia bourdieusiana com o intuito de fundamentar um importante exercício de reflexividade que o sociólogo chamou de "teoria do efeito da teoria". Para o autor,

\section{[...] a ciência social deve englobar na teoria do mundo social uma teoria do efeito da teoria, que ao contribuir para impor uma maneira mais ou menos autorizada de ver o mundo social contribui para fazer a realidade desse mundo. (BOURDIEU, 1998a, p. 82).}

Dito de outra forma, conhecer os antecedentes históricos, ao menos em linhas gerais, da produção sociológica e epistemológica reservada ao campo das práticas esportivas é condição primeira para ser possível entender, sob diferentes ângulos, os próprios problemas que são colocados sobre este espaço, já que as disposições acadêmicas legitimadas pelo corpo de especialistas que se debruçam sobre o esporte, muitas vezes, condicionam os pesquisadores a terem um olhar mais ou menos "treinado" a respeito das tensões demandadas no próprio campo esportivo.

Movimento, Porto Alegre, v. 16, n. 01, p. 293-315, janeiro/março de 2010. 
Para romper exatamente com essa persuasão imposta pelos universos de produção científica é que Bourdieu advoga em favor de que os sociólogos façam uma história social dos problemas, dos objetos e dos instrumentos de pensamento, de modo que se instaure um movimento de ruptura com o "pré-construído douto" e com o "bom senso científico". De maneira mais concisa e como garante Bourdieu:

\begin{abstract}
Para se não ser objeto dos problemas que se tomam para objecto, é preciso fazer a história social da emergência desses problemas, da sua constituição progressiva, quer dizer, do trabalho coletivo - frequentemente realizado na concorrência e na luta - o qual foi necessário para dar a conhecer e fazer reconhecer estes problemas como problemas legítimos, confessáveis, publicáveis, públicos, oficiais [...]. (BOURDIEU, 1989, p. 37).
\end{abstract}

Assim, antes de olhar sociologicamente para o campo esportivo, é necessário se debruçar sobre o campo de produção sociológica constituída em torno deste campo ${ }^{4} \mathrm{ou}$, em termos equivalentes, realizar um trabalho social sobre a elaboração dos instrumentos de construção dessa própria realidade social legitimada academicamente enquanto objeto de estudo. Nisso consiste encarar a teoria do mundo social e a teoria do conhecimento como partes de uma mesma etapa do fazer sociológico.

Avançando na exposição dos argumentos, convém notar que Bourdieu, embora tenha se debruçado sobre o esporte, não foi um sociólogo do esporte como muitos confundem. Ao invés disso, recuperou o esporte (dentre outros inúmeros objetos tidos como insignificantes no âmbito das ciências sociais) enquanto um objeto digno de ser abordado cientificamente no universo de produção sociológica.

Conforme Bourdieu, o esporte, a moda, o jornalismo - objetos aparentemente "fúteis" e "indignos" - geralmente cativam aqueles pesquisadores que se situam do lado dominado no campo, isto é, do lado

\footnotetext{
${ }^{4}$ Alguns primeiros trabalhos já vêm sendo realizados no Brasil com o intuito de sistematizar a produção de conhecimento no campo da sociologia do esporte. Um estudo que merece destaque nesse sentido é: FERREIRA, A. L. P. O estado da arte da sociologia do esporte no Brasil: um mapeamento da produção bibliográfica de 1997 a 2007. Dissertação (Mestrado em Sociologia). Universidade Federal do Paraná, Curitiba, 2009.

Movimento, Porto Alegre, v. 16, n. 01, p. 293-315, janeiro/março de 2010.
} 
que procura instaurar a heresia e impor uma nova definição de objetos legítimos. Ocorre também desses objetos, que a representação dominante tende a encarar como inferiores, muitas vezes atraírem os pesquisadores que estão menos preparados para tratá-los, o que colabora para que os princípios de visão e divisão do campo permaneçam exatamente como estão. (BOURDIEU, 1998c, p. 35-38). Em outros termos, isso equivale a entender que a ciência e os objetos definidos como únicos e legítimos são resultado das lutas objetivas entre ortodoxia e heterodoxia, entre aqueles que buscam conservar a estrutura e aqueles que buscam subvertê-la.

Substanciado por uma visão combativa e provocativa dessas relações fomentadas nos campos de produção científica, a fórmula que Bourdieu recomenda para combater essa hierarquia social das coisas boas de serem ditas e estudadas em ciências sociais é demasiado instigante e incisiva:

O cume da arte, em ciências sociais, está sem dúvida em ser-se capaz de pôr em jogo "coisas teóricas" muito importantes a respeito de objetos ditos "empíricos" muito precisos, frequentemente menores na aparência, e até mesmo um pouco irrisórios. (BOURDIEU, 1989, p. 20)

Por sua vez, esse novo modus operandi que consiste em trazer à luz do debate objetos de pesquisa consagrados academicamente como de menor importância surge, nesse sentido, tanto como condição quanto como provável efeito da imersão de Bourdieu no campo da altacostura, no campo jornalístico, nos campos de produção artística e no campo esportivo que aqui está em voga mais incisivamente.

O primeiro texto de Bourdieu versando sobre a temática do esporte se trata do artigo "Esporte e classe social" de 1978, ${ }^{5}$ seguido prontamente da publicação do capítulo "O habitus e o espaço dos estilos de vida" como parte integrante do livro "A distinção" em 1979. Rapidamente falando, em tais ocasiões, o autor procurou retomar o esporte como uma das práticas aptas a distinguir socialmente os agentes

${ }^{5}$ Para uma análise mais acurada ver : BOURDIEU, P. Sport and social class, Social Science Information sur les Sciences Sociales, v. 17, n. 6, p. 819-940, 1978.

ovimento, Porto Alegre, v. 16, n. 01, p. 293-315, janeiro/março de 2010. 
segundo sua participação nas mesmas. Anos mais tarde, em 1987, Bourdieu redigiu o texto-chave "Programa para uma sociologia do esporte", publicado na última parte do livro "Coisas ditas". 6

Ao pensar na constituição de um campo esportivo como locus de análise durante a escrita desses textos evocados, Bourdieu se vale do princípio das homologias dos espaços de produção cultural, material e simbólica, o que, consequentemente, remete a uma economia geral dos campos como lógica de trabalho constituída segundo o auxílio do método comparativo/relacional. Sobre esses ajustes metodológicos Bourdieu é enfático:

\begin{abstract}
O raciocínio analógico, que se apoia na intuição racional das homologias (ela própria alicerçada no conhecimento das leis invariantes dos campos), é um espantoso instrumento de construção do objeto. É ele que permite mergulharmos completamente na particularidade do caso estudado sem que nela nos afoguemos, como faz a idiografia empirista, e realizarmos a intenção de generalização, que é a própria ciência, não pela aplicação de grandes construções formais e vazias, mas por essa maneira particular de pensar o caso particular que consiste em pensá-lo verdadeiramente como tal. (BOURDIEU, 1989, p. 32-33).
\end{abstract}

Em suma, o que Bourdieu argumenta é que existem propriedades universais (homólogas) que regulam o funcionamento dos mais diversos campos. E muito mais que isso, que ao se avançar na compreensão de um determinado campo seguramente constrói-se um referencial que permite entender, amiúde, as reservas e contingências apresentadas em outros campos.

Não obstante, o cuidado que Bourdieu dispensa na lapidação desse tipo de raciocínio é minucioso e excessivo de tal modo que ele próprio não caia na frequente armadilha com que se deparam os cientistas sociais: o de acabarem universalizando o caso particular. Inclu-

\footnotetext{
${ }^{6}$ Para fins de esclarecimento, é importante frisar que o texto "Esporte e classe social" foi publicado pela segunda vez por Bourdieu em 1980 no livro "Questões de sociologia" e com o título "Como se pode ser esportivo?". Já o artigo "Programa para uma sociologia do esporte" foi reapresentado pelo sociólogo no segundo número de Sociology of Sport Journal de 1988.
}

Movimento, Porto Alegre, v. 16, n. 01, p. 293-315, janeiro/março de 2010. 
sive, é exatamente para evitar esse tipo de equívoco que Bourdieu já justifica a natureza dos campos como sendo relativamente autônoma, o que, de antemão, pressupõe a vigência de leis e propriedades específicas e redutíveis a cada um destes universos.

O conceito de campo foi inicialmente pensado por Bourdieu para dar conta da aplicabilidade do estruturalismo à sociedade francesa. Com o passar do tempo, entretanto, essa noção vai sendo lapidada, ganhando, assim, mais corpo de aplicações, como a cultura e a educação, por exemplo. Aideia de Bourdieu, em termos mais precisos, era autonomizar as referidas áreas em relação às explicações economicistas. (CHARTIER, 2002).

Dentre esses espaços, que possuem cronologia própria e uma história estrutural relativamente autônoma da esfera econômica e política, encontra-se o campo esportivo. Enquanto locus social delimitado pela análise bourdieusiana, o campo esportivo, a propósito dos demais campos, também se trata de um espaço estruturado onde há dominantes e dominados que disputam os capitais específicos em jogo e buscam conservar a estrutura ou então transformá-la. Além disso, esse campo, como qualquer outro espaço social, desenvolve uma doxa e um nomos que lhe são pertinentes, ou seja, um senso comum que atribui lógica ao campo e um conjunto de leis invariantes que regulamentam as ações dos agentes.

Para desenvolver uma abordagem sobre um campo como, por exemplo, o das práticas esportivas, Bourdieu sugere alguns passos metodológicos a serem seguidos. De acordo com o sociólogo, um primeiro passo seria analisar a posição que o referido campo ocupa frente ao campo do poder. Em seguida, é necessário traçar um mapa da estrutura objetiva das relações ocupadas pelos agentes ou instituições que competem pela forma legítima de autoridade específica no campo. Por fim, devem ser analisados os habitus dos agentes, isto é, os diferentes sistemas de disposições adquiridos em relação ao campo. (BOURDIEU; WACQÜANT, 2008).

Na esteira dessas considerações, é possível afirmar, portanto, que a constituição de um campo relativamente autônomo das práticas esportivas se institui na medida em que se considera a incidência dos habitus

Movimento, Porto Alegre, v. 16, n. 01, p. 293-315, janeiro/março de 2010. 
esportivos nesse espaço, já que, como ensina Bourdieu, o campo estrutura o habitus em tão presente medida que o habitus constitui o campo. (BOURDIEU, 1998b). Decorre dessa interpretação, que o habitus se trata, antes, de um corpo socializado, um corpo estruturado, um corpo que, enfim, incorporou "[...] as estruturas imanentes de um mundo ou de um setor particular desse mundo, de um campo, e que estrutura tanto a percepção desse mundo quanto a ação nesse mundo". (BOURDIEU, 2007b, p. 144).

Nesse sentido, os habitus funcionam como um programa de percepção, classificação e organização da ação; uma espécie de força que mantém e sustenta determinada ordem social. Exatamente por isso é que o habitus se apresenta e se distingue enquanto "princípio unificador e gerador de todas as práticas". Como sistemas de disposições duráveis e incorporados pelos agentes, os habitus tendem a reproduzir a estrutura objetiva de que são produtos. (BOURDIEU, 2003a, p.54).

Por conta dessa leitura relacional e pautando-se, além disso, na ideia da objetividade de apreensão dos fatos sociais conservada na sociologia de Pierre Bourdieu, pode-se extrair o argumento e consideração metodológica de que a noção de campo é, em certo sentido, "uma estenografia conceptual de um modo de construção do objeto que vai comandar - ou orientar - todas as opções de prática de pesquisa". (BOURDIEU, 1989).

Mais precisamente, é a noção de campo que possibilita ao pesquisador cercar determinado objeto com a pretensão de taquigrafá-lo. Para isso, entretanto, esse mesmo pesquisador deve "[...] verificar que o objeto em questão não está isolado de um conjunto de relações de que se retira o essencial das suas propriedades". (BOURDIEU, 1989, p. 27).

No texto "Programa para uma sociologia do esporte" (1990b), Bourdieu discorre detalhadamente sobre cada um desses procedimentos mencionados e, deste modo, apresenta um quadro teóricometodológico de bastante consistência para se estudar a estruturação do campo esportivo. Um primeiro aspecto sugerido pelo sociólogo diz respeito ao fato de que um pesquisador não podendo estudar o espaço das práticas esportivas como um todo, deveria recortar um subespaço

Movimento, Porto Alegre, v. 16, n. 01, p. 293-315, janeiro/março de 2010. 
dentro desse espaço, isto é, delimitar um subcampo a fim de desenvolver sua respectiva análise.

Outro ponto essencial consiste em relacionar esse subcampo evidenciado aos demais subespaços que constituem o campo esportivo, para então reconhecer a posição que ele ocupa na referida estrutura. Por fim, e instaurando uma dialética entre estruturas micro e macrossociológicas, outro aspecto metodológico de singular importância seria identificar o espaço das posições sociais manifestos nos subcampos e no campo esportivo em sua totalidade.

Para levar adiante tal empreendimento, Bourdieu reconhece antecipadamente o campo esportivo como um lugar condicionante $\mathrm{e}$ condicionado pela história social das práticas esportivas. Esse argumento se encontra desenvolvido com bastante clareza no texto "Como é possível ser esportivo?" (1983b), quando então o sociólogo introduz uma série de questionamentos sobre as origens do fenômeno social que se aceita como "esporte moderno" e, mais especificamente, sobre o momento histórico em que as práticas esportivas com seus agentes, organismos e instituições mantenedoras passaram a funcionar como um campo específico.

De outro modo, e nas palavras do próprio Bourdieu, um dos objetivos centrais de uma teoria social do esporte seria saber:

[...] como se constituiu este espaço de jogo, com sua lógica própria, este lugar com práticas sociais inteiramente particulares, que foram definidas no curso de uma história própria e que só podem ser compreendidas a partir desta história [...]?". (BOURDIEU, 1983b, p. 138).

Essa preocupação de Bourdieu com a historicidade do campo esportivo - esse espaço trabalhado pelas contingências históricas - deve ser compreendida relacionalmente à trajetória imprimida em seu pensamento sociológico no findar dos anos 1970. Nesse propósito, José Sérgio Leite Lopez em debate com o historiador francês Roger Chartier, faz questão de frisar que as obras produzidas por Bourdieu a partir de 1980 evidenciam um maior compromisso dele com a temática da história. (CHARTIER, 2002).

Movimento, Porto Alegre, v. 16, n. 01, p. 293-315, janeiro/março de 2010. 
Ainda nessa ocasião, o mesmo Chartier atribui uma lógica explicativa para a crescente recorrência histórica nas análises bourdieusianas, principalmente no que tange as contínuas lapidações de conceitos como campo ou habitus segundo um viés de historicidade. De acordo com Chartier, isso se explica ao considerar-se a própria história de vida de Pierre Bourdieu, sua relação com a disciplina histórica e sua interlocução com os historiadores. (CHARTIER, 2002).

Quanto à forma como Bourdieu trabalha a dimensão histórica nas ciências sociais e, em específico, na sociologia, é necessário assinalar algumas particularidades. Primeiramente, ele atribui uma nítida vantagem à descontinuidade histórica, isto é, não se interessa pelos grandes processos de burocratização, racionalização e modernização, os quais, segundo sua forma de encarar o metier sociológico " [...] trazem muitas vantagens sociais a seus autores e pouco proveito científico". (BOURDIEU, 1990a, p. 57).

Segundo, que a dimensão do campo, enquanto um espaço constituído na esteira de uma história estrutural de transformações, não representa um processo linear garantido por regras previamente definidas ou enquanto produto de um cálculo racional dos agentes. Pelo contrário, a história de um campo muda à medida que agentes e instituições entram no jogo, à medida que novos interesses substituem os antigos e outros objetos de disputa passam a orientar a rede de relações e atrair a atenção dos jogadores.

No entanto, muitas vezes os leitores de Bourdieu não se dão conta de tais pressupostos e passam a utilizar a noção de campo de forma mecânica, esquecendo-se que o mesmo deve ser abordado na perspectiva de sua constituição histórica ou então, e em maior proximidade ao modelo bourdieusiano, estabelecendo uma comparação estrutural entre os vários momentos de sua história relativamente autônoma e não necessariamente linear. Sobre esses usos desatentos do conceito de campo, Chartier comenta:

Creio que trabalhar com Bourdieu aplicando mecanicamente a categoria de campo seria introduzir a ideia de uma categoria universal sem dar suficiente atenção às descontinuidades. E há em Bourdieu também, uma proposta de descontinuidade. Não se trata de um

Movimento, Porto Alegre, v. 16, n. 01, p. 293-315, janeiro/março de 2010. 
pensamento da necessidade, nem da consequência, nem da continuidade. (CHARTIER, 2002, p. 167).

Essa fala de Chartier, em imediato reforça que a continuidade histórica não parece ter sido o foco principal da perspectiva sociológica bourdieusiana, ao contrário, por exemplo, de Norbert Elias, que ao preocupar-se com os grandes processos civilizacionais europeus atribuiu um papel secundário ao advento de "pontos de ruptura", embora insistentemente lembre que a teoria do processo de civilização é passível de "pontos cegos", os quais, por sua vez, não foram trabalhados mais detidamente pelo autor.

Adote-se como exemplo mais específico dessas nuanças sugeridas sobre a obra de Elias, a gênese do esporte moderno, já que a mesma se situa na "[...] continuidade do estudo do processo de civilização, isto é, em linha direta com aquilo que constitui por excelência o tema eliasiano". (GARRIGOU, 2001, p. 67).

Para Elias, a gênese do esporte moderno é uma das principais evidências de que o processo de civilização que descrevera durante a Idade Média não estaria encerrado. $\mathrm{O}$ autor procura demonstrar esse "impulso civilizador" dos esportes pelo viés da "esportização", ou seja, da crescente passagem ou, até mesmo, substituição dos jogos antigos e tradicionais pelas práticas esportivas modernas.

Não obstante, essa linha de continuidade apresentada por Elias para explicar o surgimento do esporte moderno em favor do desaparecimento dos jogos tradicionais (folk games) apresenta algumas fragilidades, embora em muitos casos, como o futebol e o boxe, por exemplo, as teses eliasianas estejam extremamente compatíveis. Bourdieu sintetiza melhor essas impressões:

Además, Elias es más sensible que yo a la continuidad. El análisis histórico de tendencias de largo prazo es siempre susceptible de rupturas críticas ocultas. Tomemos el ejemplo del programa de investigación histórica sobre los deportes que Elias esboza en su conocido "Ensayo sobre los deportes y la violencia". Al delinear una genealogía continua que va desde los juegos de la Antigüedad a los Juegos Olímpicos de

Movimento, Porto Alegre, v. 16, n. 01, p. 293-315, janeiro/março de 2010. 


\begin{abstract}
hoy, este texto conlleva el peligro de enmascarar las rupturas fundamentales introducidas, entre otras cosas, por el surgimiento de los sistemas educativos, los colleges ingleses y los internados, como así también por la subsecuente constitución de un "espacio de los deportes" relativamente autónomo. No hay nada en común entre los juegos rituales del tipo del soule medieval y el futbol americano. (BOURDIEU; WACQÜANT, 2008, p. 129-130).
\end{abstract}

Importante reiterar que em nenhum momento dessa fala, Bourdieu desconsidera ou rejeita a abordagem eliasiana sobre a história processual do esporte, até porque a mesma é academicamente legitimada como uma das matrizes sociológicas de maior consistência para estudar o processo de surgimento do esporte moderno. No entanto, Bourdieu tece alguns contrapontos que, no mínimo, instigam a questionar a perspectiva eliasiana.

Sucintamente falando, e até mesmo em congruência com o escopo de análise desenvolvido em seus programas de pesquisa, pode-se admitir que Bourdieu ligeiramente se ocupa daqueles chamados momentos de ruptura que quase escapam à história. Daí sua sensibilidade em perceber que a passagem do jogo ao esporte propriamente dito tenha se realizado nas grandes escolas reservadas às elites da sociedade burguesa.

Além disso, o autor aponta que foi a partir dessas instituições que o esporte se difundiu para as associações esportivas de massa, onde recebeu um sentido completamente novo e que mantém estreita ligação com o surgimento de um universo relativamente autônomo das práticas esportivas.

Em síntese, Bourdieu circunscreve o surgimento do campo esportivo - esse espaço estruturado, mas também estruturante - como um momento de descontinuidade na história dos esportes. Nesse sentido, ao pensar a origem das práticas esportivas modernas, Bourdieu percorre um caminho inverso ao de Norbert Elias, demonstrando que na própria esteira da civilização, "esportização", "cortenização", existem outras vias mais sutis, ocultas e, até mesmo, decisivas no processo de desenvolvimento dos esportes modernos.

Movimento, Porto Alegre, v. 16, n. 01, p. 293-315, janeiro/março de 2010. 
Um último aspecto de fundamental importância a ser recuperado do modelo de análise sociológica do campo esportivo de Pierre Bourdieu é a estruturação de um quadro analítico e interpretativo que permite compreender devidamente a distribuição e orientação dos consumos e das práticas esportivas na sociedade. Para isso, o sociólogo sistematiza uma economia cultural dos bens esportivos pautado na relação entre, de um lado, a oferta - bens esportivos oferecido aos agentes sob a forma de práticas e consumos - e de outro, a demanda - orientada pelo gosto e pelas transformações nos estilos de vida.

A partir dos pressupostos conceituais bourdieusianos, pode-se entender por demanda da prática de esportes o ato dos agentes estarem jogando voleibol, lutando boxe ou disputando uma partida de tênis, dentre outras possibilidades. Já o consumo esportivo passivo se evidencia quando os agentes estão acompanhando uma partida de futebol pela TV ou compram uma camiseta do time que torcem, ou ainda, quando crianças e adolescentes passam a se comportar de acordo com os estereótipos e padrões disseminados através da transmissão de espetáculos esportivos na mídia e que incitam modos de vestir, de falar, de se alimentar e, de uma forma mais específica, escolher redes de sociabilidade e convivência.

Ao pensar nas formas como se apresentam os consumos e as práticas esportivas, Bourdieu procura estabelecer relação imediata com as posições sociais. Segundo o sociólogo (1983b, p. 143), na medida em que se desce na hierarquia social a probabilidade de um agente praticar esporte depois da adolescência, isto é, quando adulto ou idoso, diminui nitidamente. Já quanto à possibilidade de assistir aos espetáculos esportivos mais populares, essa decresce na medida em que os agentes sobem na hierarquia social. Conforme Bourdieu:

\footnotetext{
Os lucros distintivos são dobrados quando a distinção entre as práticas distintas e distintivas, como os esportes "chiques", e as práticas que se tornaram "vulgares", devido à divulgação de vários esportes originalmente reservados à "elite", como o futebol [...] é acrescida da oposição, mais marcada ainda, entre a prática do esporte e o simples consumo de espetáculos esportivos. (BOURDIEU, 1983b, p. 143).
}

Movimento, Porto Alegre, v. 16, n. 01, p. 293-315, janeiro/março de 2010. 
Assim, é possível perceber a formação de um campo esportivo substanciado pela tônica da dicotomia entre esporte-prática e esporteespetáculo; entre esporte de elite e esporte de massa. Contudo, outras oposições também se vinculam a este campo, como as que seguem reiteradas: amadorismo contra o profissionalismo; esporte de lazer versus esporte de competição; esportes de contato direto e esportes à distância; esportes que requerem maior atividade intelectual e menor dispêndio físico versus esportes que solicitam maior uso da força e menor capacidade de reflexão, e os exemplos se multiplicam.

Decorre desses sistemas de classificação e dicotomias, que o esporte em si confere um estilo de vida distintivo aos seus consumidores e praticantes. Em outros termos, o esporte moderno na forma como é consumido e praticado se demonstra perfeitamente compatível e complacente com a lógica da estrutura de organização do espaço social, ou melhor, enquanto um campo onde estão em jogo as próprias definições legítimas da prática esportiva e dos usos diferenciados que se pode fazer do corpo nos esportes.

Aliás, é nesse mesmo espaço social configurado que se definem os gostos dos agentes, através de uma alquimia das classificações imanente ao jogo e que, muito mais que indicar que "[...] o motor de todas as condutas humanas seria a busca da distinção" (BOURDIEU, 2007b, p. 22-23), demonstra que existir em um espaço é diferir, é ser diferente, é ser classificado e, ao mesmo tempo, classificante. Dessa forma, é perfeitamente compreensível que para haver gostos,

\footnotetext{
[...] é preciso que haja bens classificados, de "bom" ou "mau" gosto, "distintos" ou "vulgares", classificados e ao mesmo tempo classificantes, hierarquizados e hierarquizantes, e que haja pessoas dotadas de princípios de classificações, de gostos, que lhes permitam perceber entre estes bens aqueles que lhes convém, aqueles que são “do seu gosto". (BOURDIEU, 1983a, p. 127).
}

Essa capacidade de percepção, apreciação, enfim, de escolhas de práticas, equivale a ter o sentido do jogo - habitus - impresso, tatuado no corpo, ou seja, incorporado nas formas de determinado

Movimento, Porto Alegre, v. 16, n. 01, p. 293-315, janeiro/março de 2010. 
agente agir, encarar e se situar no espaço social. O gosto então enquanto conjunto de práticas e de propriedades de uma pessoa ou grupo funciona como "[...] operador prático da transmutação das coisas em sinais distintos e distintivos [...]" (BOURDIEU, 2007a, p. 166), possibilitando que as diferenças de ordem material se convertam em diferenças de ordem simbólica e vice-versa.

Tais constatações possibilitam encarar o gosto como sendo o produto do encontro de duas histórias - uma objetivada e outra incorporada. História objetivada porque está diretamente relacionada à exposição de bens e práticas nos campos de produção cultural, ou seja, à exteriorização da oferta segundo sanções de uma economia propriamente não econômica que apresenta objetos e produtos classificados. E história incorporada porque se interioriza nos agentes os sistemas de classificação que lhes permitem escolher, dentro dos limites impostos pela estrutura e de maneira não consciente (embora não se possam descartar as intenções e transições conscientes), entre os bens e práticas disponíveis e precedentes ao gosto em si.

O esporte é uma dessas práticas classificadas, classificantes e classificadoras. Não obstante, os próprios produtos e bens culturais atrelados, direta ou indiretamente, à indústria do esporte também o são; definem posições distintivas a serem antecipadas por agentes dotados do senso de percepção e apreciação requisitada. E isso essencialmente porque o esporte e os bens culturais correlatos se tratam de práticas objetivamente classificadas e com potencialidade a se converter em práticas classificadoras, isto é, a se tornarem um lucro e expressão simbólica da condição de classe.

Deste modo, não seria equivocado dizer que as diferentes posições ocupadas pelos agentes no espaço social correspondem a estilos de vida mais ou menos ajustados, e, além disso, que os "gostos de classe" são a consequente incorporação da estrutura do espaço social através da experiência dóxica desses mesmos agentes em uma região determinada do referido espaço. ${ }^{7}$

${ }^{7}$ Para uma discussão mais aprofundada ver: BOURDIEU, P. Gostos de classe e estilos de vida In: ORTIZ, R, (org.). A sociologia de Pierre Bourdieu. São Paulo: Olho d'Água, 2003b. p. 73-111.

Movimento, Porto Alegre, v. 16, n. 01, p. 293-315, janeiro/março de 2010. 
Na definição dos estilos de vida, ou melhor, na "estilização da vida" é que residem, portanto, as variações que balizam os gostos. Por sua vez, o gosto pode se exprimir de duas formas complementares, ou seja, contemplando as exigências impostas pela necessidade dos agentes e grupos, ou então, como estratégia cuja expectativa é suprir um estilo de vida distintivo e condizente com as posições ocupadas. Dessas impressões, sucessivamente, derivam dois conceitos-chave desenvolvidos por Bourdieu no livro "A distinção" (2007a): consumo cultural distinto e consumo cultural vulgar.

No primeiro caso, o consumo é entendido exatamente pela raridade e distinção social que engendra. Já no segundo caso, a banalidade e o fácil acesso ao produto, bem ou prática, representa o código de vulgaridade investido no jogo. Assim, o consumo distinto pressupõe um acúmulo razoável de capital econômico e cultural, ao passo que o consumo vulgar, geralmente, está desprovido do volume desses capitais.

A propósito, o conceito de capital é de suma importância e capilaridade para entender a dinamicidade com que se organiza o espaço social, sobretudo no que tange a definição do gosto e dos estilos de vida. Para tanto, Bourdieu procura ampliar a noção de capital para além do poder explicativo de que esse conceito se revestia nas abordagens marxistas, demonstrando que, para compreender as trocas simbólicas permeadas nos mais distintos campos sociais, pode-se recorrer à figura analógica da economia, na medida em que o capital se apresenta como um recurso que tende a conferir lucros distintivos a quem o possui.

Decorre, consequentemente, dessa leitura, a existência de tantas variedades de capitais em jogo como campos propriamente ditos. De acordo com Bourdieu, os espaços sociais, ao se constituírem como campos, produzem formas de interesse específicas e que, por sua vez, podem ser consideradas como desinteresse no ponto de vista dos demais campos de produção material e cultural. (BOURDIEU, 2007b).

Deste modo, seria um equívoco pensar a relação entre o consumo distinto e vulgar de forma determinista e mecânica, o que, consequentemente, camuflaria a existência de uma posição intermediária. Para Bourdieu, esse projeto não é válido, já que entre o consumo distinto e

Movimento, Porto Alegre, v. 16, n. 01, p. 293-315, janeiro/março de 2010. 
vulgar existem zonas intermediárias povoadas por práticas pretensiosas, pela discordância dos agentes e pelas disputas envolvendo o monopólio dos capitais específicos. (BOURDIEU, 2007a).

Acresça-se, em última instância, a essa análise, que os capitais que obtém predominância nas estratégias de distinção e nas disputas entre agentes e estruturas no interior do campo esportivo, são o capital econômico, cultural e social, exatamente nessa ordem. (BOURDIEU, 1983b). Além disso, o maior ou menor provimento do volume desses capitais potencialmente define o envolvimento dos agentes em determinadas práticas esportivas, bem como o acesso aos produtos esportivos correlatos, numa dinâmica que possibilita tanto à conversão do capital econômico e cultural em capital simbólico, quanto ao contrário, o que, de certo modo, evidencia a dinamicidade dos agentes diante da construção de um "gosto de classe".

Em síntese e amparado nessa arquitetura teórica pautada na relação entre habitus, campo e capital, Bourdieu (1983b, 1990b) circunscreve o campo esportivo como um lugar de disputas pela definição legítima da prática esportiva e das funções legítimas das atividades esportivas, lembrando que dessas lutas, que são lutas para impor novos princípios de visão e divisão no campo, resultam estilos de vida distintivos, que denotam as estratégias dos agentes como um locus de "escolhas" e "investimentos", os quais além de diferenciá-los, refletem as condições sociais e objetivas de sua própria produção.

Aliás, é sempre bom reiterar que essas mesmas lutas pelas classificações implicam na composição de um campo de forças; um campo de forças que, dentre outros fatores, é transmudado em função das lutas pela legitimação do corpo e dos usos que se pode fazer dele nos esportes; um campo de forças, mas, acima de tudo, um campo de lutas para transformar ou conservar esse campo de forças. Daí a potencialidade e propensão das relações fomentadas no universo dos esportes se constituírem de modo a opor treinadores, jogadores, torcedores, comerciantes e consumidores de bens e serviços esportivos, dentre outros agentes que se movimentam no espaço social.

Movimento, Porto Alegre, v. 16, n. 01, p. 293-315, janeiro/março de 2010. 


\section{ConsideraçõEs PARA o FECHAMENTO}

O esforço intelectual suscitado na construção do presente artigo se desdobrou no sentido de recuperar e ainda sistematizar, no interior de um quadro de análise bem específico e situado, alguns dos pressupostos teórico-metodológicos bourdieusianos inerentes à constituição de uma sociologia propriamente reflexiva do esporte.

Cabe aqui reiterar que, embora muitos estudiosos das práticas esportivas ponderem que Bourdieu não estruturou no corpo de sua obra uma unidade homogênea de análise a ponto que se pudesse denominar "teoria sociológica do esporte", de fato o sociólogo fundou e inaugurou um modelo teórico dos mais consistentes para analisar sociologicamente a estruturação e disseminação do fenômeno esportivo contemporâneo.

Essa intenção, de certa forma, foi promovida e reforçada no próprio escopo editorial da revista Actes de La Recherche en Sciences Sociales, que sob a direção de Bourdieu reservou algumas edições para discutir os consumos e práticas esportivas. É oportuno notar que já no segundo ano de circulação da revista, em 1976, houve um número específico destinado para discutir a relação entre esporte, violência e estado.

Uma década mais tarde, novamente o esporte foi recuperado pelo editorial da revista, com dois números publicados, respectivamente, em setembro e novembro de 1989. Em junho de 1994, foi publicado o volume 103 da revista abordando a temática do futebol. Recentemente, em setembro de 2009, houve uma nova inserção do esporte enquanto objeto de análise em Actes de La Recherche en Sciences Sociales. Trata-se do volume 179 da revista, que com a temática "Pratiques martiales et sports de combat", reitera o compromisso deste veículo de circulação dos bens científicos com objetos que talvez ainda sejam considerados e tratados como "menores" no campo da sociologia.

Por fim, é imperativo admitir que, objetivamente, não se estabelece e nem muito menos se consolida uma teoria sociológica do esporte em Pierre Bourdieu, ao considerá-la autônoma e independentemente

Movimento, Porto Alegre, v. 16, n. 01, p. 293-315, janeiro/março de 2010. 
do modelo epistemológico (sociologia reflexiva) e metodológico (teoria da prática) aprimorado, aperfeiçoado e revisitado pelo autor ao longo de sua obra. Aliás, tal compartimentalização equivaleria a fornecer uma visão um tanto quanto injusta do trabalho de um sociólogo que combateu avidamente os reducionismos advindos do olhar sociológico substancialista.

Deste modo, vislumbra-se uma teoria sociológica do esporte em Pierre Bourdieu enquanto um prolongamento de seu método de investigação reflexivo e praxiológico. Também se reitera a importância de não estender e transferir mecanicamente as ferramentas conceituais bourdieusianas (habitus, campo, capital) para potencializar a análise do esporte, o que talvez contribua para que se "reproduza" no universo acadêmico a ideia de que seu modelo analítico direcionado à leitura do fenômeno esportivo não se trata de uma teoria sociológica do esporte, mas de um esquema rígido de investigação isolado de um conjunto de habitus sociológicos que orientam e guiam, de maneira mais profunda, a construção de seu pensamento e de sua obra.

Além disso, é na retomada desse olhar que talvez consista a essência do pensamento relacional, tal como Bourdieu insistia, aplicado objetivamente à análise das categorias "impensáveis" e balizadoras de seu próprio pensamento sociológico; um olhar que, por vezes, não é desenvolvido pelos limites de apropriação acadêmica de sua obra mas também e, impreterivelmente, pelas barreiras colocadas nos campos científicos a uma sociologia que, dentre outras incursões, propõe-se a entender a própria trama do jogo "jogado" nos campos científicos.

Movimento, Porto Alegre, v. 16, n. 01, p. 293-315, janeiro/março de 2010. 


\begin{abstract}
For a reflexive sociology of sport: theoretical and metodological considerations based on Pierre Bourdieu's work

Abstract: This article intended to present and discuss some relevant aspects of reflectivity of the sporting field theory of Pierre Bourdieu. For this aim was felt the necessity of focus in three points of theorical and metodological sustenance worked rigorously by the author, which are: (1) to epistemological reflexivity; (2) the play of the historical knowledge in the sociological analyses of the sport; (3) the direction of sporting consumption in the sense of a social space consolidation associated to the logic of the distinction.
\end{abstract}

Keywords: Sociology. Sports. Pierre Bourdieu.

\begin{abstract}
Por una sociología reflexiva del deporte: consideraciones teóricas y metodológicas sobre la base del trabajo de Pierre Bourdieu

Resumen: En presente artículo demanda presentar y discutir algunos aspectos de la reflexividad constituyentes de la teoría del campo deportivo de Pierre Bourdieu. Por esa intención, sintió la necesidad de centrarse en tres puntos de apoyo teórico y metodológico trabajado estrictamente por el autor, a saber: (1) reflexión epistemológica, (2) el papel del conocimiento histórico en el análisis sociológico del deporte; (3) la orientación del consumo de los deportes con el fin de consolidar un espacio social asociado a la lógica de la distinción.

Palabras clave: Sociología. Deportes. Pierre Bourdieu.
\end{abstract}

\title{
REFERÊNCIAS
}

BOURDIEU, J. Pratiques martiales et sports de combat. Actes de la Recherche en Sciences Sociales, Paris, v. 179, n. 6, p. 04-179, sep. 2009.

BOURDIEU, P. Le sport, l'Etat et la violence. Actes de la Recherche en Sciences Sociales, Paris, v. 2, n. 6, p. 02-89, déc. 1976.

Sport and social class, Social Science Information sur les Sciences Sociales, Paris, v. 17, n. 6, p. 819-940, 1978.

Questões de sociologia. Rio de Janeiro: Marco Zero, 1983a.

Como é possível ser esportivo? In: Questões de sociologia. Rio de Janeiro: Marco Zero, 1983b, p.136-153.

Movimento, Porto Alegre, v. 16, n. 01, p. 293-315, janeiro/março de 2010. 
L'espace des sports-1. Actes de la Recherche en Sciences Sociales, Paris, v.79, p. 02-115, sep. 1989.

. L'espace des sports-2. Actes de la Recherche en Sciences Sociales, Paris, v.80, p. O2-102, nov. 1989.

. Introdução a sociologia reflexiva. In:

O poder simbólico. Lisboa: Difel, 1989. p. 18-56;

Coisas ditas. São Paulo: Brasiliense, 1990a.

Programa para uma sociologia do esporte. In . Coisas ditas. São Paulo: Brasiliense, 1990b. p. 207-220.

Les enjeux du football. Actes de la Recherche en Sciences Sociales, Paris, v. 103, p. 03-11, jui. 1994

A economia das trocas linguísticas. São Paulo: EDUSP, 1998a.

A economia das trocas simbólicas. São Paulo: Perspectiva, 1998b.

Método científico e hierarquia social dos objetos. In: NOGUEIRA, M. A.;

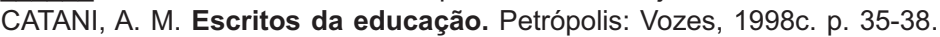

. Esboço de uma teoria da prática. In: ORTIZ, R, (org.). A sociologia de Pierre Bourdieu. São Paulo: Olho d’Água, 2003a. p. 39-72.

Gostos de classe e estilos de vida. In: ORTIZ, R, (org.). A sociologia de Pierre Bourdieu. São Paulo: Olho d'Água, 2003b.p. 73-111.

Esboço de auto-análise. São Paulo: Companhia das Letras, 2005. Zouk, 2007a.

A distinção: crítica social do julgamento. São Paulo: Edusp; Porto Alegre:

Razões práticas: sobre a teoria da ação. Campinas,SP: Papirus, 2007b.

BOURDIEU, P.; WACQUANT, L. An invitation to reflexive sociology. Chicago: The University of Chicago, 1992.

Una invitación a la sociología reflexiva. 2. ed. Buenos Aires: Siglo XXI Editores Argentina, 2008.

BOURDIEU, P.; CHAMBOREDON, J-C.; PASSERON, J-C. A profissão de sociólogo: preliminares epistemológicas. Petrópolis: Vozes, 1999.

CATANI, A. M. As apropriações da obra de Pierre Bourdieu no campo educacional brasileiro. Revista Portuguesa de Educação, Braga, v.15, n. 1, p.5-25, 2002.

CHARTIER, R. Bourdieu e a História: Debate com José Sérgio Leite Lopez. Topoi, Rio de Janeiro, v. 3, p. 139-182, mar. 2002.

Movimento, Porto Alegre, v. 16, n. 01, p. 293-315, janeiro/março de 2010. 
FERREIRA, A. L. P. O estado da arte da sociologia do esporte no Brasil: um mapeamento da produção bibliográfica de 1997 a 2007. Dissertação (Mestrado em Sociologia). Universidade Federal do Paraná, Curitiba, 2009.

GARRIGOU, A. O "grande jogo" da sociedade. In: GARRIGOU, A.; LACROIX, B. (orgs.). Norbert Elias: a política e a história. São Paulo: Editora Perspectiva, 2001. p. 65-88.

MEDEIROS, C. C. C. A teoria Sociológica de Pierre Bourdieu na produção discente dos programas de Pós-Graduação em Educação no Brasil (1965-2004). Tese (Doutorado em Educação). Universidade Federal do Paraná, Curitiba, 2007.

MEDEIROS, C. C. C; MARCHI JÚNIOR, W. Para uma Sociologia da Educação: considerações a partir da obra de Pierre Bourdieu. In: BRANDÃO, C. F. (Org.). Intelectuais do Século XX e a Educação no século XXI: o que podemos aprender com eles? Marília: Poïesis, 2009. p. 99-119.

MONTAGNER, M. A. Pierre Bourdieu, o corpo e a saúde: algumas possibilidades teóricas. Ciência e Saúde Coletiva, Rio de Janeiro, v. 11, n. 2, p.515-526, jun. 2006.

Pierre Bourdieu e a saúde: uma sociologia em Actes de la Recherche en Sciences Sociales. Cadernos de Saúde Pública, Rio de Janeiro, v. 24, n. 7 , p.1588-1598, jul. 2008.

NOGUEIRA, C. M. M.; NOGUEIRA, M. A. A Sociologia da Educação de Pierre Bourdieu: limites e contribuições. Educação e Sociedade, Campinas, v. 23, n. 78, p.15-35, abr. 2002.

WACQUANT, L. Durkheim e Bourdieu: a base comum e suas fissuras. Novos Estudos, CEBRAP, São Paulo, n. 48, p. 29-38, jul. 1997.

Hacia una praxeología social: la estructura y la lógica de la sociología de Bourdieu. In: BOURDIEU, P.; WACQUANT, L. Una invitación a la sociología reflexiva. 2. ed. Buenos Aires: Siglo XXI Editores Argentina, 2008. p. 25-90.

Movimento, Porto Alegre, v. 16, n. 01, p. 293-315, janeiro/março de 2010. 